\title{
REVIEW
}

\section{Clinical review: flow cytometry perspectives in the ICU - from diagnosis of infection to monitoring of injury-induced immune dysfunctions}

\author{
Fabienne Venet ${ }^{1,2}$, Alain Lepape $e^{2,3}$ and Guillaume Monneret',2*
}

\begin{abstract}
Septic syndromes represent a major healthcare problem worldwide. Clinical and experimental evidence indicates that septic patients rapidly present with numerous compromised immune functions. Although flow cytometry remains a relatively confidential diagnostic tool, it could be useful at every step of ICU patient management. Indeed, neutrophil CD64 expression is a sensitive and specific tool for diagnosis of sepsis in adults, neonates and children. Diminished monocyte HLA-DR expression is a reliable marker for the development of monocyte anergy, prediction of secondary nosocomial infection and death in critically ill patients. Finally, the measurement of an increased $\mathrm{CD}^{+}{ }^{+} \mathrm{CD} 25^{+} \mathrm{CD} 127^{\text {low }}$ regulatory T-cell percentage may represent a reliable marker for the diagnosis of lymphocyte dysfunctions in these patients. Ideally, these biomarkers should be part of a panel helping to define ICU patients' immune status. The potential of flow cytometry is further illustrated by use of the biomarkers listed above as stratification tools in preliminary clinical studies. Importantly, many other markers of immune dysfunctions are currently under development that could further enable the administration of targeted individualized therapy in ICU patients. The next critical step would be to use these standardized flow cytometry protocols in large multicentric clinical trials testing individualized immunotherapy.
\end{abstract}

\section{Sepsis pathophysiology}

Septic syndromes represent a major, although largely under-recognized, healthcare problem worldwide

*Correspondence: guillaume.monneret@chu-lyon.fr

'Hospices Civils de Lyon, Immunology Laboratory, Hôpital E. Herriot, 5 place d'Arsonval, 69437 Lyon cedex 03, France

Full list of author information is available at the end of the article accounting for thousands of deaths every year [1,2]. Mortality remains high, ranging from $20 \%$ for sepsis to over $50 \%$ for septic shock despite almost 20 years of antiinflammatory clinical trials $[1,2]$. The inability of these therapies to mitigate the devastating effects of this condition indicates that the initial hypotheses for sepsis pathophysiology may have been misconstrued or inadequately addressed. Two major explanations have been proposed: septic patients have mainly been treated as a group despite the extreme heterogeneity characterizing this population [1]; and the postulate that death after sepsis is solely due to an overwhelming proinflammatory immune response may actually be inaccurate $[1,2]$.

Indeed, several lines of evidence now establish that death from septic shock is probably due to the effects of distinct mechanisms over time [1,2]. Early in the course of the disease, a massive release of inflammatory mediators (normally designated to trigger immune response against pathogens) is occurring that may be responsible for organ dysfunctions and hypoperfusion $[1,2]$. Concomitantly, the body develops compensatory mechanisms to prevent overwhelming inflammation and dampen an overzealous anti-infectious response [1,2]. These negative feedback mechanisms, although having protective effects during the initial hours, may paradoxically become deleterious as they persist over time, leading to immune suppression (Figure 1) [1,2]. Indeed, considerable clinical and experimental evidence indicates that patients rapidly present with numerous compromised immune functions [1,2]. As our capacity to treat patients during the very first hours of shock has improved (early and aggressive initial supportive therapy) [1], many patients now survive this critical step but eventually die later in a state of immunosuppression that is illustrated by patients' difficulty to fight the primary bacterial infection, decreased resistance to secondary nosocomial infections and reactivation of viral infections normally solely pathogenic in an immunocompromised host [1-3].

Consequently, immunostimulatory therapies are now considered an innovative strategy for the treatment of 


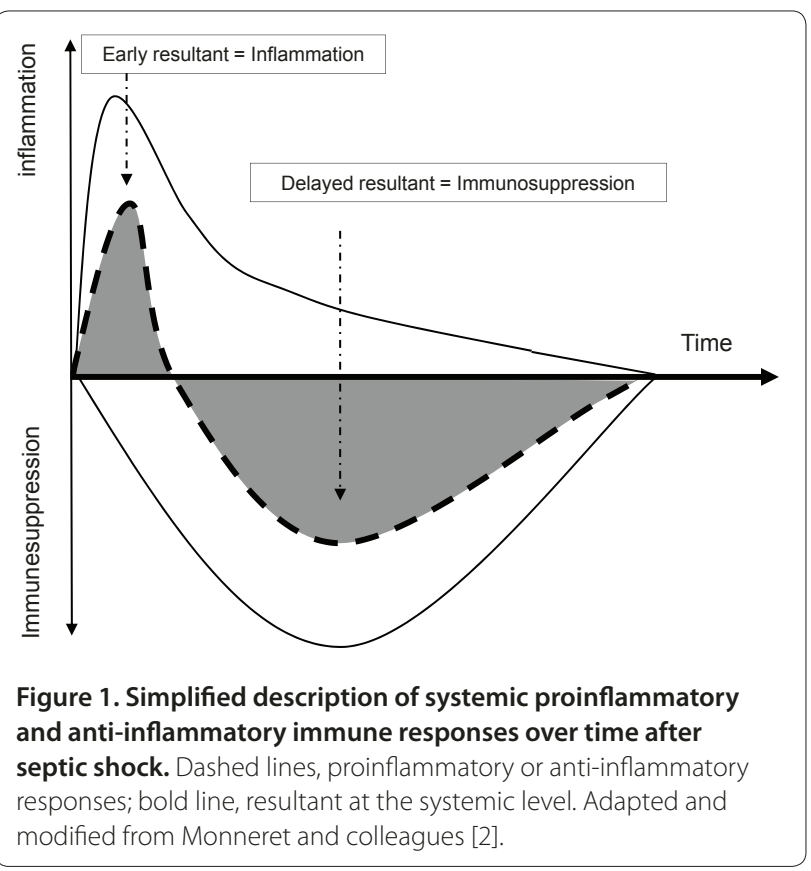

sepsis [1,2]. The first critical step, however, is to identify patients who would actually benefit from these therapies [2]. Indeed, in the absence of specific clinical signs of their immune response, it is therefore critical to determine the best biological tools for patient stratification according to their immune status (a missing step in most of previous clinical trials) [1,2]. This would define the right action (that is, stimulating innate immunity and/or adaptive immunity, blocking apoptosis, restoring other altered functions) at the right time (early or delayed treatment) in the right patient (individualized/tailored therapy).

In this context, we will show that flow cytometry (FCM) could be useful at every step of ICU patient management: from the diagnosis of infection to the definition of targeted and individualized therapy, and finally - and most importantly - for the control of drug efficacy.

\section{General facts about flow cytometry}

Despite marked improvements over the past decades, FCM still remains a relatively confidential diagnostic tool. Indeed, clinical situations in which FCM is used on a routine basis are still limited (for example, lymphoma and leukemia phenotyping, CD4 ${ }^{+} \mathrm{T}$-cell counting in HIVinfected patients, basophil testing in allergy, diagnosis of paroxysmal nocturnal hemoglobinuria, and so forth).

Several reasons could explain such poor development in clinics. First, FCM suffers from its lack of standardization. Indeed, FCM is an open technique and is therefore difficult to standardize whereas very reproducible protocols are mandatory for multicentric clinical studies [4]. In fact, as opposed to automated clinical chemistry analyzers, the measurement of a new parameter by FCM offers the possibility to set up homemade protocols (that is, to define a staining and a gating strategy, a lysis system and an appropriate acquisition protocol). Second, FCM refers to immunology and hematology, meaning supposedly complex fields easily accessible only to specialists. This is especially true when considering the expending universe of immune pathways and the continuously increasing number of clusters of differentiation measurable by FCM. Indeed, most clinicians do not want any other fashionable biomarker without knowing what to do with the results. Similarly, although we can multiply the number of colors detectable by sophisticated flow cytometers, the final and crucial step remains the application of the new biomarker in impact studies. Third, not being considered a commonly available routine tool (that is, available on a 24/7 basis), access to FCM facilities is not often easy for clinicians. Despite these limitations, however, we strongly believe that FCM is ready for the prime time and vulgarization, especially in the context of ICU patient monitoring.

Indeed, although the mechanistic and molecular bases for sepsis-induced immunosuppression are not exhaustively established, several features of the condition have been already described including enhanced leukocyte apoptosis, lymphocyte anergy and deactivated monocyte functions $[1,2]$. In that context, FCM is undeniably the best tool so far for monitoring immune cell functions. Indeed, as opposed to circulating molecules, the major advance in measuring a cell surface marker by FCM is that its level of expression is the result of the sum of the effects of multiple mediators, all of which are potentially regulated during septic shock [2]. Finally, harmonizing protocols, commercially available standards for results comparison across laboratories (calibrated beads, stabilized cell blood), internal controls (provided by manufacturers) and external controls (for example, UK National External Quality Service) are now available and should contribute to improve standardization and thus enable the use of FCM in multicentric clinical trials. Furthermore, it is noteworthy to mention that new technical developments (low-cost compact portable flow cytometer, bedside FCM or chip-based FCM) are now being proposed that will facilitate the use of FCM at the bedside in the ICU [5]. For now, this equipment remains devoted to very simple applications, but we may expect major developments in the forthcoming years, including multicolor FCM.

The present review will focus on biomarkers measurable by FCM on a routine standardized basis and usable for the diagnosis of sepsis (CD64 expression on 
neutrophil) and for prediction of adverse outcome, occurrence of secondary nosocomial infections or guidance of putative immunotherapy relative to innate (HLADR expression on monocytes) and adaptive (percentage of circulating $\mathrm{CD} 4{ }^{+} \mathrm{CD} 25^{+}$regulatory $\mathrm{T}$ cells) immune dysfunctions.

\section{ICU patient monitoring by flow cytometry Diagnosis of severe infections in ICU patients: CD64 expression on neutrophils}

Infection remains a major healthcare problem in hospitals, and especially in the ICU where seriously ill patients with impaired immunity are readily exposed to pathogenic microorganisms. Antibiotherapy, if appropriate and given early during the course of the infection, has been shown to reduce mortality fivefold in patients with septic shock [6]. It is thus of vital importance for clinicians to detect severe infections at an early stage, when effective treatment and complete recovery are still possible. Usual biomarkers of infection such as procalcitonin or Creactive protein lack specificity [7]. In particular, procalcitonin has been shown to be a poor diagnosis marker of infection although it is reliable for the monitoring of antibiotic efficacy $[8,9]$.

Recently, neutrophil CD64 has been shown to be a highly sensitive and specific marker for systemic infection and sepsis [7]. The membrane molecule defined by monoclonal antibody CD64 is a high-affinity receptor (Fc $\gamma \mathrm{RI})$ found on normal monocytes and only expressed at low levels by normal neutrophils. Neutrophil CD64 expression is regulated in a graded fashion in parallel with the degree of inflammatory response to a significant clinical process of infection or tissue injury [10]. Indeed, neutrophil CD64 is one of many activation-related antigenic changes manifested by neutrophils during the normal pathophysiologic acute inflammatory response. CD64 expression differs, however, from the parallel changes of increased CD45RA and CD11b/18 expressions, as well as loss of expression of CD16, CD62L, and CD66b, in that the normal baseline CD64 expression on neutrophils is negligible. Additionally, CD64 expression is stable at room temperature for more than 30 hours, in contrast to the labile expression of CD11b and other neutrophil antigens. In that sense, neutrophil CD64 has been shown to be a highly sensitive ( $>95 \%)$ and specific marker for systemic infection and sepsis in adults, neonates and children [7,11-16]. Moreover, the first results showed that CD64 measurement could allow clinicians to discontinue antimicrobial treatment if negative within 24 hours of suspected infection, without waiting for the definitive microbiological results [17]. These preliminary results now need to be confirmed in larger cohorts of patients including appropriate control groups with systemic inflammatory response syndromes. Moreover, the role of CD64 in differentiating bacterial and viral infection should be clarified, since CD64 was also found to be elevated in some viral infections $[15,18]$.

To note, a diagnostic kit is currently available that allows rapid and precise quantitative measurement of neutrophil CD64 expression (Leuko64; Trillium Diagnostics, Brewer, ME, USA). Moreover, since CD64 expression is stable in ethylenediamine tetraacetic acidanticoagulated blood for at least 24 hours at room temperature, it is well suited for application in any clinical laboratory having access to a flow cytometer. Additionally, the Leuko64 assay can be performed on hematology blood counters that use fluorescence flow cytometric principles, such as those produced by Abbott Diagnostic and by Horiba-ABX $[10,19]$. This test is almost fully automated, the results are available rapidly ( $<20$ minutes) and the assay can be performed on a 24/7 basis without specific expertise in FCM [19].

\section{Diagnosis of monocyte dysfunctions in ICU patients: HLA-DR expression on monocytes}

Monocytes from septic patients are mainly characterized by a decreased capacity to mount a proinflammatory reaction upon a secondary bacterial challenge and by impairment in antigen presentation capacity, most probably due to the lowered expression of major histocompatibility complex class II molecules. Regarding molecules expressed on monocytes, which are readily measured by standardized FCM protocols, numerous studies have been performed regarding the measurement of HLA-DR expression.

Monocytes strongly express HLA-DR on their surfaces. This molecule can thus easily be detected by FCM (Figure 2). Monocytes with diminished or missing HLADR expression are markedly inhibited in their antigenpresenting function and in their ability to produce inflammatory mediators in response to a stimulus $[2,20,21]$.

In septic patients, a decreased cell-surface expression of HLA-DR has regularly been observed on circulating monocytes (mHLA-DR) and there is now a general consensus that a diminished mHLA-DR expression is a reliable marker for the development of immunosuppression in critically ill patients [2] (Figure 2). Indeed, decreased mHLA-DR expression has been assessed as a predictor of septic complications after trauma, after surgery, after pancreatitis, in burn patients and after septic shock. In these studies, low levels of mHLA-DR were observed in patients who subsequently developed nosocomial infections [2,22-25]. In contrast, in injured patients with uneventful recovery, mHLA-DR rapidly returned to normal values (generally in less than 1 week). Finally, decreased mHLA-DR has been shown to be predictive of adverse outcome in different groups of 


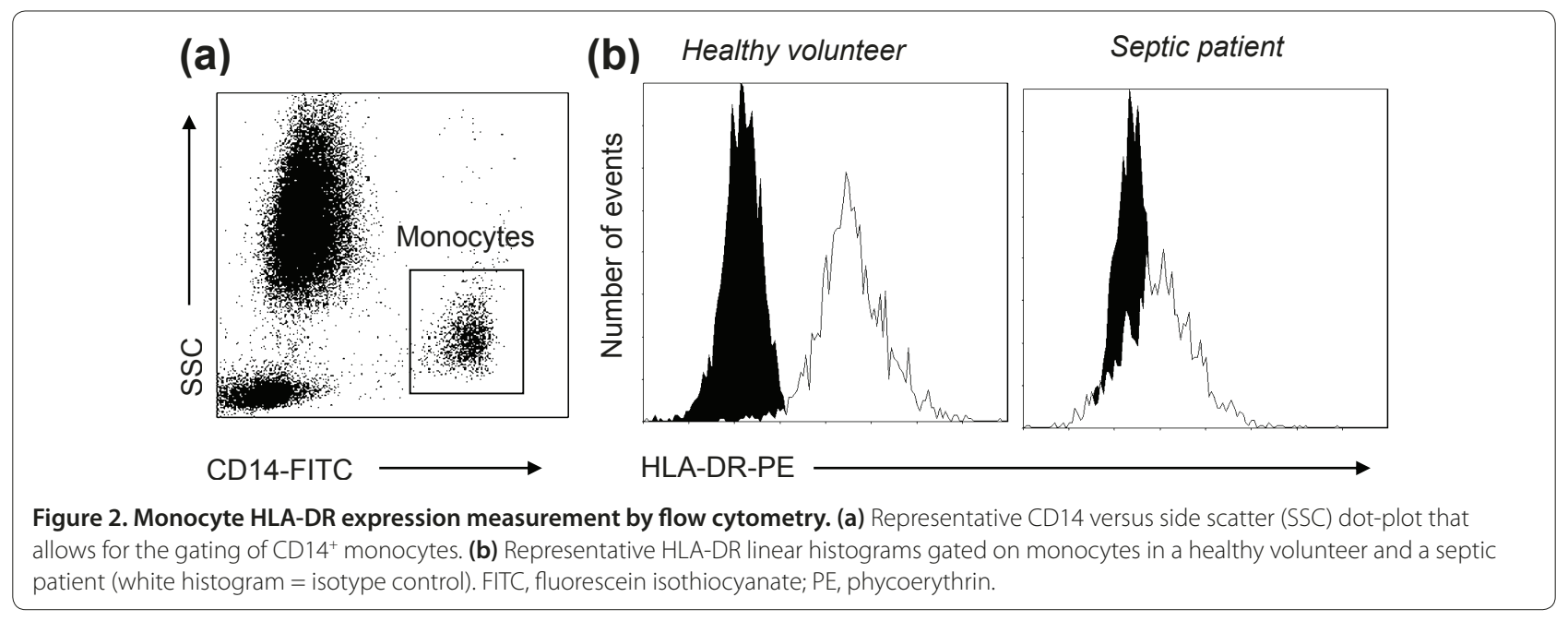

critically ill patients, including burn and septic shock patients [2,22].

Of note, because HLA-DR is a marker that is rapidly regulated, the storage temperature and the delay before staining are important issues. Use of ethylenediamine tetraacetic acid blood, storage of unprocessed blood on ice as soon as possible before staining and staining within 4 hours after blood drawing were the conditions that produced the lowest variance between $e x$ vivo values [20].

Finally, the level of expression of HLA-DR on monocytes can be measured either as the percentage of cells positive for this marker or as the mean fluorescence intensity of this marker on total monocytes (Figure 3). Both expression types are used in the literature, but no study has so far been conducted to compare the predictive value of HLA-DR when measured as a percentage or as the mean fluorescence intensity. Important to mention, however, is that results in mean fluorescence intensity cannot be compared between laboratories. To circumvent this issue and using calibrated beads, kits enabling the calculation of the number of antibodies bound per cell have been developed. This latter approach has been validated during a multicentric evaluation [20]. In this study, it was established that the usual threshold of $30 \%$ HLA-DR-positive monocytes (retained in several clinical studies for predicting mortality in septic patients) is similar to 5,000 antibodies bound per cell (Figure 3).

\section{Diagnosis of T-lymphocyte dysfunctions in ICU patients: percentage of circulating $\mathrm{CD} 4{ }^{+} \mathrm{CD} 25^{+} \mathrm{CD} 127^{\text {low }}$ regulatory T cells}

Owing to their ability to interact not only with cells of the innate immune system but also with other cells of the adaptive response, $\mathrm{T}$ lymphocytes play a central role in anti-infectious immune response both as effectors and regulators of this response. This has been illustrated by the description of an increased mortality, a decreased bacterial clearance and an altered proinflammatory immune response after polymicrobial septic challenge in mice lacking both $T$ cells and $B$ cells $[26,27]$. A growing body of evidence has now confirmed that the lymphocytemediated immune response may be dysfunctional after severe sepsis and may play a major role in the development of a state of immunosuppression in patients [28,29].

T-lymphocyte dysfunctions after severe sepsis include the occurrence of a state of anergy with a decreased proliferation to mitogen stimulation, a shift toward a Th2 profile of cytokine secretion, an increased apoptosis and an increased percentage of $\mathrm{CD} 4{ }^{+} \mathrm{CD} 25^{+}$regulatory T lymphocytes (Tregs) $[1,2,28,30]$.

Tregs have recently been reported as a potent regulatory T-cell lineage playing an essential role in the control of both adaptive and innate immune responses [31]. An increased Treg percentage has been described in septic shock patients [28]. Importantly, this increase was observed immediately after the diagnosis of sepsis, but persisted only in nonsurviving patients in association with an augmented CTLA-4 expression [32]. A similar increase in Treg percentage has been observed in trauma patients and in mice after polymicrobial septic challenge and stroke [28]. We recently observed a strong correlation between the increased Treg/effector ratio measured in whole blood after septic shock and the decreased proliferative response of patients' lymphocytes after mitogenic stimulation [33]. This suggests not only that the measurement of the Treg percentage may represent a reliable marker for the diagnosis of lymphocyte dysfunctions in patients, but also that these cells may play a central role in the development of immunoparalysis after sepsis.

In mice, although activated murine $\mathrm{CD} 4^{+} \mathrm{T}$ cells express $\mathrm{CD} 25$, the $\mathrm{CD} 4^{+} \mathrm{CD} 25^{+}$phenotype identifies a 
(a) -Isotypecontrol (setup of positive threshold)

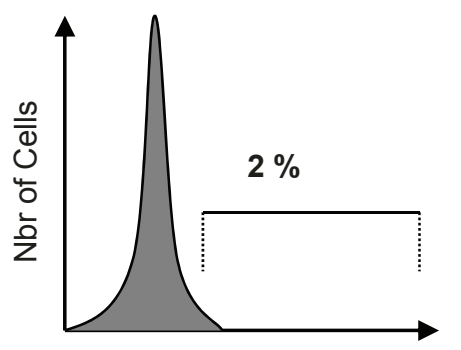

Fluorescence Intensity

(b) -Percentages

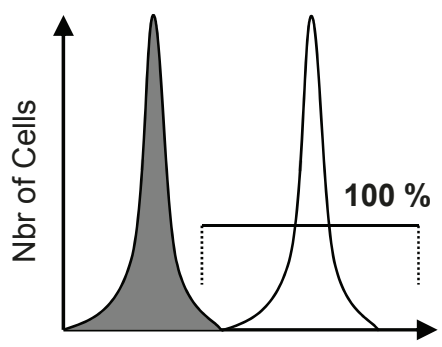

Fluorescence Intensity

(c) -Meanfluorescence intensity

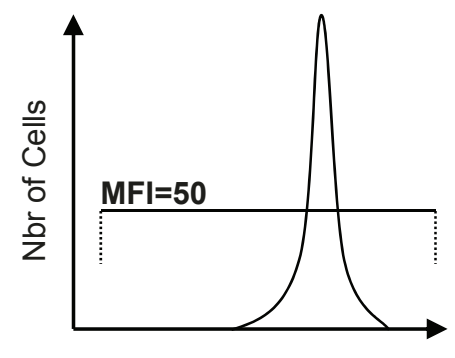

Fluorescence Intensity
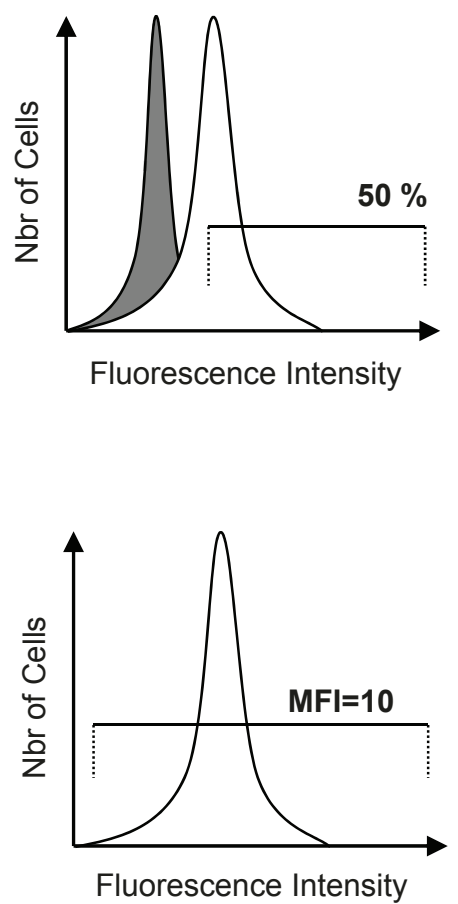

Figure 3. Measurement of percentage or mean fluorescence intensity by flow cytometry (theoretical histograms). (a) Isotype control (gray peak), a nonrelevant immunoglobulin labeled with similar fluorochrome as the staining antibody. This identifies nonspecific staining and enables one to set up a region of positive/specific staining (usually set up between 1 and 2\%). (b) Percentages. After setting up the region of positive staining using isotype control, staining with specific antibody is acquired. In healthy volunteers (left histogram) about 100\% of circulating monocytes express HLA-DR, whereas in septic shock patients (right histogram) this percentage is decreased. (c) Mean fluorescence intensity (MFI). The average intensity of fluorescence on all cells of interest is measured. In cases of circulating monocyte human leukocyte antigen-DR expression (mHLA-DR) measurements, the gated region includes all monocytes and the MFI value is decreased in septic patients (right histogram) in comparison with the normal value (left histogram). However, the measurement of this parameter is highly dependent on the flow cytometer settings and cannot be compared between two laboratories. To circumvent this, kits using calibrated beads and calculating the number of antibodies bound per cells (AB/C) have been developed. Regarding mHLA-DR expression, the usual threshold of 30\% positive monocytes (retained in several studies for predicting mortality after sepsis) is similar to 5,000 AB/C [20].

largely homogeneous regulatory population. In humans, however, complications arise because of the presence of a sizeable population of activated $\mathrm{CD} 4^{+} \mathrm{T}$ cells that express CD25 [34]. Although the human $\mathrm{CD} 4{ }^{+} \mathrm{CD} 25^{\text {hi }}$ population is the most efficient in terms of suppression, there is no uniformly defined consensus on where the boundary between CD25 ${ }^{\text {hi }}$ and CD2 $5^{\text {int }}$ expression occurs. Comparing results directly has therefore been difficult, in terms of both Treg numbers and functionality, from studying human clinical samples, particularly in inflammatory 
conditions where there are significant numbers of activated effector $\mathrm{T}$ cells [34]. The $\mathrm{CD} 4{ }^{+} \mathrm{CD} 25^{+}$phenotype is therefore not Treg specific, and this lack of specificity is also exhibited by other surface markers, including glucocorticoid-induced TNF receptor family-related protein, CTLA-4, CD45RB, CD62L, neuropilin-1, CD103 and lymphocyte activation gene 3 , which have shown enriched expression in Treg populations [34].

A more specific marker is the forkhead box P3 transcription factor. This marker can only be used to isolate cells that are permeabilized and fixed, however, and the staining procedure is long (around 3 hours for completion) [35]. Awaiting new reagents and protocols for rapid intracellular staining, specific surface markers are thus needed to allow consistent identification and functional testing of Tregs.

Two groups have recently addressed these issues by identifying the utility of CD127 expression for discriminating between Tregs and activated T cells [34,36,37]. In adult human whole blood, both studies associated the phenotype of $\mathrm{CD} 4{ }^{+} \mathrm{CD} 25^{+} \mathrm{CD} 127^{\text {low }}$ cells with intracellular forkhead box P3 expression - suppressive and hypoproliferative activities therefore identifying Tregs [35]. In human whole blood this population represents approximately 6 to $8 \%$ of total $\mathrm{CD}^{+} \mathrm{T}$ cells [34].

We verified that the combined expressions of $\mathrm{CD} 4$ and CD25 and the low of expression of CD127 appeared adequate for the characterization of circulating Tregs in whole blood of either healthy volunteers or septic shock patients [33]. A significant increase in the percentage of circulating $\mathrm{CD} 4{ }^{+} \mathrm{CD} 25^{+} \mathrm{CD} 127^{\text {low }}$ Tregs in septic shock patients was measured in comparison with healthy individuals, which was mainly due to a decrease in the $\mathrm{CD} 4{ }^{+} \mathrm{CD} 25^{+} \mathrm{CD} 127^{\text {low }} \mathrm{T}$-cell number rather than a rise in the Treg count after sepsis [33]. This study showed the validity of the three-color FCM staining (CD4/CD25/ CD127) for the standardized routine monitoring of Tregs in patients (Figure 4). The measurement of CD127 in addition with CD4 and CD25 thus allows for a rapid (below 30 minutes) and standardizable estimation of Treg numbers, usable in multicentered clinical studies. In ICU patients, therefore, the measurement of Treg and conventional T-cell frequency or absolute count $\left(\mathrm{CD} 4^{+}\right.$ T-cell enumeration is doable on the same tube used for Treg identification) may represent simple and valuable surrogate markers of lymphocyte anergy usable on a routine basis for the monitoring of sepsis-induced immune dysfunctions. Once again, the relative predictive values of these parameters need to be confirmed in large multicentric clinical evaluations because, to date, only few studies (including small cohorts of patients) investigated the association between lymphocyte alterations and clinical outcome (nosocomial infections, mortality) in ICU patients.

\section{Perspective}

Targeted individualized therapy based on FCM-measured biomarkers

FCM could represent an innovative diagnostic tool in many clinical situations (allergy, transplantation, autoimmunity, and so forth), especially since this technique can also be used for the measurement of soluble markers (a point that has not been addressed here).

In the specific clinical context of ICU patient monitoring, the potential of FCM is further demonstrated by the use of the biomarkers listed above as stratification tools in preliminary clinical studies testing immunomodulating therapies. In particular, several clinical trials have recently used the measurement of mHLA-DR expression to stratify the administration of IFN $\gamma$ or granulocyte-macrophage colony-stimulating factor in small cohorts of ICU patients [25,38-41]. These studies showed promising results and such a strategy should now be tested in clinical trials including a large number of patients.

Moreover, several other innovative immunotherapies may be proposed for the treatment of immune dysfunctions in ICU patients based on the initial measurement of biomarkers by FCM (Table 1). In particular, recombinant human IL-7 represents an interesting candidate. This molecule is an essential cytokine for Tlymphocyte development, survival, expansion and maturation in humans [42]. Phase I clinical trials in cancer and HIV-infected patients have shown that T-cell expansion can be achieved at doses that are well tolerated [42]. Phase II clinical trials in HIV-infected patients showed that IL-7 can significantly expand $\mathrm{CD}_{4}^{+}$and $\mathrm{CD}^{+} \mathrm{T}$ cells with lower expression of programmed death 1. Importantly, in murine models of sepsis (cecal ligation and puncture), studies have shown the capacity of recombinant human IL-7 to improve survival, block apoptosis, restore lymphocyte functions (IFNY production), improve effector cell recruitment and prevent loss of delayed-type hypersensitivity $[43,44]$. Preliminary results in children with severe bacterial infections showed that the plasmatic IL-7 level was increased in survivors in comparison with nonsurvivors [45]. In sepsis, the administration of recombinant human IL-17 could be stratified based on the assessment of lymphocyte anergy.

Finally, beside the markers listed in the present article, other markers of immune dysfunctions measurable by FCM have been proposed. These include markers of apoptosis, increased co-signaling receptor expression, measurement of intracellular co-signaling pathways or circulating cytokine dosages using beads (Table 1). For example, increased programmed death 1-related molecule expressions have been described in murine models of sepsis [46] and in sepsis patients [47]. As antiprogrammed death 1 blocking antibodies are currently 


\section{(a)}

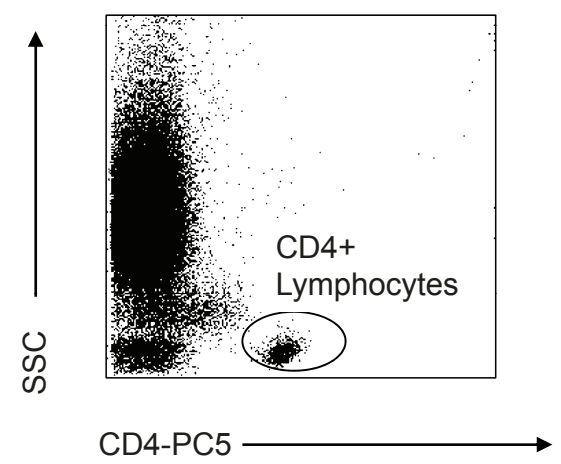

(b)

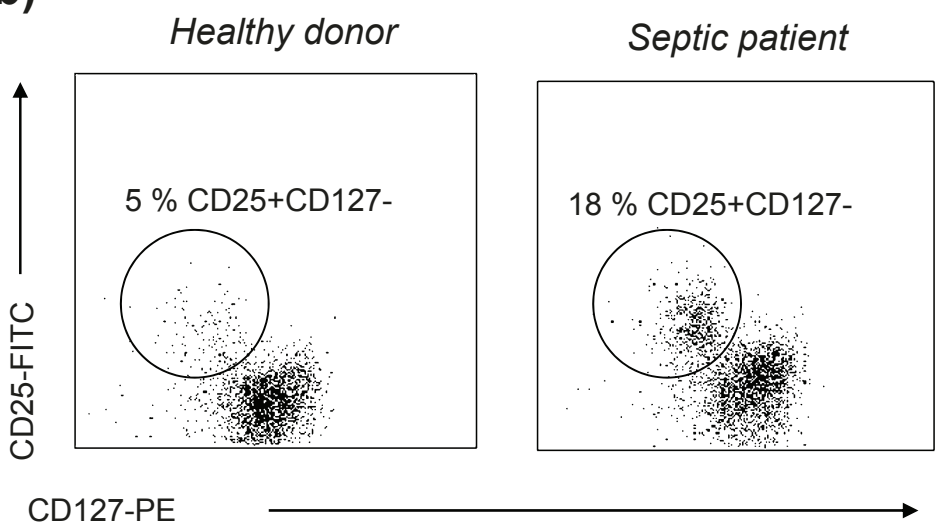

Figure 4. CD4 ${ }^{+} \mathrm{CD} 25^{+} \mathrm{CD} 127^{\text {low }}$ regulatory T-cell measurement by flow cytometry. (a) Representative CD4 versus side scatter (SSC) dot-plot that allows for the gating of $C D 4^{+}$lymphocytes (Ly). (b) Gated on CD4+ Ly, representative CD25 versus CD127 dot-plots in one healthy volunteer and a septic patient. The CD25+CD127low population is easily identified and its percentage is increased in septic patients. FITC, fluorescein isothiocyanate; $P E$, phycoerythrin.

\section{Table 1. Immune dysfunctions in septic patients: potential biomarkers}

\begin{tabular}{|c|c|c|c|}
\hline \multicolumn{2}{|l|}{ Response } & \multirow{2}{*}{$\begin{array}{l}\text { Biomarker } \\
\downarrow \text { ex vivo cytokine production after TLR agonist stimulation }\end{array}$} & \multirow{2}{*}{$\begin{array}{l}\text { Flow cytometry technique } \\
\text { Cytometric bead array }\end{array}$} \\
\hline Innate immune response & Functional testing & & \\
\hline & Plasma cytokines & $\uparrow \| L-10$ & Cytometric bead array \\
\hline & Cell surface marker expression & $\downarrow \mathrm{mHLA}-\mathrm{DR}$ & Cell surface staining \\
\hline & & $\downarrow$ CD14, CD86, GM-CSFR, CX3CR1, and so forth & \\
\hline & Apoptosis & Depolarized mitochondria & Cell surface staining \\
\hline & & $\downarrow$ CD14 & \\
\hline \multirow[t]{8}{*}{ Adaptive immune response } & Functional testing & $\downarrow$ proliferation after antigenic or nonspecific stimulation & CFSE probes \\
\hline & Cell surface marker expression & $\uparrow$ inhibitory receptors: PD-1, CTLA4, CD47, and so forth & Cell surface staining \\
\hline & & $\downarrow$ co-activator receptors: CD28, CD3 & \\
\hline & & $\uparrow \% \mathrm{CD} 4^{+} \mathrm{CD} 25^{+}$regulatory $\top$ cells & \\
\hline & Apoptosis & $\downarrow T$-cell count & Cell surface staining \\
\hline & & $\uparrow$ Annexin $V$ staining & Cell surface staining \\
\hline & & $\downarrow \mathrm{BCl} 2$ expression protein/gene & Intracellular staining \\
\hline & & $\mathrm{Bax} / \mathrm{BCl}-\mathrm{xl}$ or $\mathrm{Bax} / \mathrm{BCl} 2$ ratios & \\
\hline
\end{tabular}

CFSE, carboxyfluorescein succinimidyl ester; GM-CSFR, granulocyte-macrophage colony-stimulating factor receptor; mHLA-DR, circulating monocyte human leukocyte antigen-DR expression; PD-1, programmed death 1; TLR, Toll-like receptor. 
tested in phase I clinical trials in cancer, such immunoregulatory therapy is now proposed in the treatment of sepsis [48]. Again, under standardized protocols, these aspects have to be investigated in multicentric clinical trials.

\section{Conclusion}

Patients with sepsis present with features consistent with immunosuppression, and stimulating their immune system may thus represent promising therapeutic strategies. An absolute prerequisite for the next clinical trials, however, is to initially systematically assess patients' immune functions to be able to define individualized immunotherapy. For that purpose, the measurement of biomarkers using standardized FCM protocols appears to be the appropriate tool for forthcoming years. Eventually, FCM will provide a panel of biomarkers giving clinicians an overview of the patients' immune status and thus indicate the best immunostimulating therapy to be initiated.

\section{Abbreviations}

FCM, flow cytometry; HLA, human leukocyte antigen; IFN, interferon; IL, interleukin; $\mathrm{mHLA}-\mathrm{DR}$, circulating monocyte human leukocyte antigen-DR expression; Th, T-helper type; TNF, tumor necrosis factor; Treg, CD4 ${ }^{+} \mathrm{CD} 25^{+}$ regulatory $T$ cell.

\section{Competing interests}

Beckman Coulter provides a flow cytometer (FC500) to the Clinical Immunology Laboratory (Hôpital E. Herriot, Hospices Civils de Lyon, France) to support the clinical research program on sepsis. However, the authors would like to mention that they wrote the present review in a totally independent manner without any supervision by Beckman Coulter.

\section{Acknowledgments}

The authors would like to thank Beckman Coulter and the Hospices Civils de Lyon, especially the Clinical Research Department (O Gelpi, Délégation à la Recherche Clinique et à I'Innovation) for their constant support over the years.

\section{Author details}

'Hospices Civils de Lyon, Immunology Laboratory, Hôpital E. Herriot, 5 place d'Arsonval, 69437 Lyon cedex 03, France. 'Equipe d'Accueil Mixte 4174, «Hémostase, Inflammation, Sepsis », Hospices Civils de Lyon, Université Claude Bernard Lyon 1, Faculté de Médecine Laennec, 8 rue Guillaume Paradin, 69372 Lyon cedex 08, France. ${ }^{3}$ Hospices Civils de Lyon, Intensive Care Unit, Lyon-Sud University Hospital, 165 chemin du grand Revoyet, 69495 Pierre-Bénite cedex, France.

\section{Published: 7 October 2011}

\section{References}

1. Hotchkiss RS, Karl IE: The pathophysiology and treatment of sepsis. N EnglJ Med 2003, 348:138-150.

2. Monneret G, Venet F, Pachot A, Lepape A: Monitoring immune dysfunctions in the septic patient: a new skin for the old ceremony. Mol Med 2008, 14:64-78.

3. Kalil AC, Florescu DF: Prevalence and mortality associated with cytomegalovirus infection in nonimmunosuppressed patients in the intensive care unit. Crit Care Med 2009, 37:2350-2358.

4. Owens MA, Vall HG, Hurley AA, Wormsley SB: Validation and quality control of immunophenotyping in clinical flow cytometry. J Immunol Methods $2000,243: 33-50$

5. Maecker HT, McCoy JP, Jr., Amos M, Elliott J, Gaigalas A, Wang L, Aranda R, Banchereau J, Boshoff C, Braun J, Korin Y, Reed E, Cho J, Hafler D, Davis M,
Fathman CG, Robinson W, Denny T, Weinhold K, Desai B, Diamond B, Gregersen P, Di Meglio P, Nestle FO, Peakman M, Villanova F, Ferbas J, Field E, Kantor A, Kawabata T, Komocsar W, Lotze M, Nepom J, Ochs H, O'Lone R, Phippard D, Plevy S, Rich S, Roederer M, Rotrosen D, Yeh JH: A model for harmonizing flow cytometry in clinical trials. Nat Immunol 2010, 11:975-978.

6. Kumar A, Ellis P, Arabi Y, Roberts D, Light B, Parrillo JE, Dodek P, Wood G, Simon D, Peters C, Ahsan M, Chateau D: Initiation of inappropriate antimicrobial therapy results in a fivefold reduction of survival in human septic shock. Chest 2009, 136:1237-1248.

7. Groselj-Grenc M, Ihan A, Pavcnik-Arnol M, Kopitar AN, Gmeiner-Stopar T, Derganc M: Neutrophil and monocyte CD64 indexes, lipopolysaccharidebinding protein, procalcitonin and C-reactive protein in sepsis of critically ill neonates and children. Intensive Care Med 2009, 35:1950-1958.

8. Nobre V, Harbarth S, Graf JD, Rohner P, Pugin J: Use of procalcitonin to shorten antibiotic treatment duration in septic patients: a randomized trial. Am J Respir Crit Care Med 2008, 177:498-505.

9. Tang H, Huang T, Jing J, Shen H, Cui W: Effect of procalcitonin-guided treatment in patients with infections: a systematic review and metaanalysis. Infection 2009, 37:497-507.

10. Davis BH, Olsen SH, Ahmad E, Bigelow NC: Neutrophil CD64 is an improved indicator of infection or sepsis in emergency department patients. Arch Pathol Lab Med 2006, 130:654-661.

11. Bhandari $\mathrm{V}$, Wang $\mathrm{C}$, Rinder $\mathrm{C}$, Rinder $\mathrm{H}$ : Hematologic profile of sepsis in neonates: neutrophil CD64 as a diagnostic marker. Pediatrics 2008 121:129-134.

12. Cardelli P, Ferraironi M, Amodeo R, Tabacco F, De Blasi RA, Nicoletti M, Sessa R, Petrucca A, Costante A, Cipriani P: Evaluation of neutrophil CD64 expression and procalcitonin as useful markers in early diagnosis of sepsis. Int $\mathrm{J}$ Immunopathol Pharmacol 2008, 21:43-49.

13. Dilli D, Oguz SS, Dilmen U, Koker MY, Kizilgun M: Predictive values of neutrophil CD64 expression compared with interleukin-6 and C-reactive protein in early diagnosis of neonatal sepsis. J Clin Lab Anal 2010, 24:363-370.

14. Ng PC, Li G, Chui KM, Chu WC, Li K, Wong RP, Chik KW, Wong E, Fok TF: Neutrophil CD64 is a sensitive diagnostic marker for early-onset neonatal infection. Pediatr Res 2004, 56:796-803.

15. Nuutila J, Hohenthal U, Laitinen I, Kotilainen P, Rajamaki A, Nikoskelainen J, Lilius EM: Simultaneous quantitative analysis of FcyRI (CD64) expression on neutrophils and monocytes: a new, improved way to detect infections. $\mathrm{J}$ Immunol Methods 2007, 328:189-200.

16. Icardi M, Erickson Y, Kilborn S, Stewart B, Grief B, Scharnweber G: CD64 index provides simple and predictive testing for detection and monitoring of sepsis and bacterial infection in hospital patients. J Clin Microbio/ 2009, 47:3914-3919.

17. Hoffmann JJ: Neutrophil CD64: a diagnostic marker for infection and sepsis. Clin Chem Lab Med 2009, 47:903-916.

18. Rudensky B, Sirota G, Erlichman M, Yinnon AM, Schlesinger Y: Neutrophil CD64 expression as a diagnostic marker of bacterial infection in febrile children presenting to a hospital emergency department. Pediatr Emerg Care 2008, 24:745-748.

19. van der Meer W, van Dun L, Gunnewiek JK, Roemer B, Scott CS: Simultaneous determination of membrane CD64 and HLA-DR expression by blood neutrophils and monocytes using the monoclonal antibody fluorescence capability of a routine haematology analyser. J Immunol Methods 2006, 311:207-219.

20. Docke WD, Hoflich C, Davis KA, Rottgers K, Meisel C, Kiefer P, Weber SU, Hedwig-Geissing M, Kreuzfelder E, Tschentscher P, Nebe T, Engel A, Monneret G, Spittler A, Schmolke K, Reinke P, Volk HD, Kunz D: Monitoring temporary immunodepression by flow cytometric measurement of monocytic HLA-DR expression: a multicenter standardized study. Clin Chem 2005 51:2341-2347.

21. Liu X, Zhan Z, Li D, Xu L, Ma F, Zhang P, Yao H, Cao X: Intracellular MHC class II molecules promote TLR-triggered innate immune responses by maintaining activation of the kinase Btk. Nat Immunol 2011, 12:416-424.

22. Venet F, Tissot S, Debard AL, Faudot C, Crampe C, Pachot A, Ayala A, Monneret G: Decreased monocyte human leukocyte antigen-DR expression after severe burn injury: correlation with severity and secondary septic shock. Crit Care Med 2007, 35:1910-1917.

23. Cheron A, Floccard B, Allaouchiche B, Guignant C, Poitevin F, Malcus C, Crozon J, Faure A, Guillaume C, Marcotte G, Vulliez A, Monneuse O, Monneret 
G: Lack of recovery in monocyte human leukocyte antigen-DR expression is independently associated with the development of sepsis after major trauma. Crit Care 2010, 14:R208.

24. Landelle C, Lepape A, Voirin N, Tognet E, Venet F, Bohe J, Vanhems $P$, Monneret $\mathrm{G}$ : Low monocyte human leukocyte antigen-DR is independently associated with nosocomial infections after septic shock. Intensive Care Med 2010, 36:1859-1866.

25. Lukaszewicz AC, Grienay M, Resche-Rigon M, Pirracchio R, Faivre V, Boval B, Payen D: Monocytic HLA-DR expression in intensive care patients: interest for prognosis and secondary infection prediction. Crit Care Med 2009, 37:2746-2752

26. Shelley O, Murphy T, Paterson H, Mannick JA, Lederer JA: Interaction between the innate and adaptive immune systems is required to survive sepsis and control inflammation after injury. Shock 2003, 20:123-129.

27. Hotchkiss RS, Chang KC, Swanson PE, Tinsley KW, Hui JJ, Klender P, Xanthoudakis S, Roy S, Black C, Grimm E, Aspiotis R, Han Y, Nicholson DW, Karl $\mathrm{IE}$ : Caspase inhibitors improve survival in sepsis: a critical role of the lymphocyte. Nat Immunol 2000, 1:496-501.

28. Venet F, Chung CS, Monneret G, Huang X, Horner B, Garber M, Ayala A: Regulatory T cell populations in sepsis and trauma. J Leukoc Biol 2008 83:523-535

29. Lederer JA, Rodrick ML, Mannick JA: The effects of injury on the adaptive immune response. Shock 1999, 11:153-159.

30. Remick DG: Pathophysiology of sepsis. Am J Pathol 2007, 170:1435-1444.

31. Belkaid Y: Regulatory T cells and infection: a dangerous necessity. Nat Rev Immunol 2007, 7:875-888.

32. Monneret G, Debard AL, Venet F, Bohe J, Hequet O, Bienvenu J, Lepape A: Marked elevation of human circulating $\mathrm{CD} 4^{+} \mathrm{CD} 25^{+}$regulatory T cells in sepsis-induced immunoparalysis. Crit Care Med 2003, 31:2068-2071.

33. Venet F, Chung CS, Kherouf H, Geeraert A, Malcus C, Poitevin F, Bohe J, Lepape A, Ayala A, Monneret G: Increased circulating regulatory T cells $(\mathrm{CD} 4(+) \mathrm{CD} 25(+) \mathrm{CD} 127(-))$ contribute to lymphocyte anergy in septic shock patients. Intensive Care Med 2009, 35:678-686.

34. Banham AH: Cell-surface IL-7 receptor expression facilitates the purification of FOXP3(+) regulatory T cells. Trends Immunol 2006, 27:541-544.

35. Hartigan-O'Connor DJ, Poon C, Sinclair E, McCune JM: Human CD4 ${ }^{+}$ regulatory T cells express lower levels of the IL-7 receptor alpha chain (CD127), allowing consistent identification and sorting of live cells. J Immunol Methods 2007, 319:41-52.

36. Seddiki N, Santner-Nanan B, Martinson J, Zaunders J, Sasson S, Landay A, Solomon M, Selby W, Alexander SI, Nanan R, Kelleher A, Fazekas de St Groth B: Expression of interleukin (IL)-2 and IL-7 receptors discriminates between human regulatory and activated T cells. J Exp Med 2006, 203:1693-1700.

37. Liu W, Putnam AL, Xu-Yu Z, Szot GL, Lee MR, Zhu S, Gottlieb PA, Kapranov P, Gingeras TR, Fazekas de St Groth B, Clayberger C, Soper DM, Ziegler SF, Bluestone JA: CD127 expression inversely correlates with FoxP3 and suppressive function of human CD4 ${ }^{+}$T reg cells. J Exp Med 2006, 203:1701-1711.
38. Docke WD, Randow F, Syrbe U, Krausch D, Asadullah K, Reinke P, Volk HD, Kox W: Monocyte deactivation in septic patients: restoration by IFN- $\gamma$ treatment. Nat Med 1997, 3:678-681.

39. Meisel C, Schefold JC, Pschowski R, Baumann T, Hetzger K, Gregor J, WeberCarstens S, Hasper D, Keh D, Zuckermann H, Reinke P, Volk HD: GM-CSF to reverse sepsis-associated immunosuppression: a double-blind randomized placebo-controlled multicenter trial. Am J Respir Crit Care Med 2009, 180:640-648

40. Drossou-Agakidou V, Kanakoudi-Tsakalidou F, Sarafidis K, Tzimouli V, Taparkou A, Kremenopoulos G, Germenis A: In vivo effect of rhGM-CSF and rhG-CSF on monocyte HLA-DR expression of septic neonates. Cytokine 2002, 18:260-265.

41. Nakos G, Malamou-Mitsi VD, Lachana A, Karassavoglou A, Kitsiouli E, Agnandi N, Lekka ME: Immunoparalysis in patients with severe trauma and the effect of inhaled interferon-gamma. Crit Care Med 2002, 30:1488-1494.

42. Sportes C, Gress RE: Interleukin-7 immunotherapy. Adv Exp Med Biol 2007, 601:321-333.

43. Unsinger J MM, Kasten KR, Hoekzema AS, Watanabe E, Muenzer JT, McDonough JS, Tschoep J, Ferguson TA, McDunn JE, Morre M, Hildeman DA, Caldwell CC, Hotchkiss RS: IL-7 promotes T cell viability, trafficking, and functionality and improves survival in sepsis. J/mmuno/ 2010 184:3768-3779.

44. Kasten KR, Prakash PS, Unsinger J, Goetzman HS, England LG, Cave CM, Seitz AP, Mazuski CN, Zhou TT, Morre M, Hotchkiss RS, Hildeman DA, Caldwell CC: Interleukin-7 (IL-7) treatment accelerates neutrophil recruitment through gamma delta T-cell IL-17 production in a murine model of sepsis. Infect Immun 2010, 78:4714-4722.

45. Carrol ED: Comment on 'L-15 prevents apoptosis, reverses innate and adaptive immune dysfunction, and improves survival in sepsis' and comment on 'IL-7 promotes T cell viability, trafficking, and functionality and improves survival in sepsis'. J Immunol 2010, 15:789-790.

46. Huang X, Venet F, Wang YL, Lepape A, Yuan Z, Chen Y, Swan R, Kherouf H, Monneret G, Chung CS, Ayala A: PD-1 expression by macrophages plays a pathologic role in altering microbial clearance and the innate inflammatory response to sepsis. Proc Natl Acad Sci U S A 2009, 106:6303-6308.

47. Guignant C, Lepape A, Huang X, Kherouf H, Denis L, Poitevin F, Malcus C, Cheron A, Allaouchiche B, Gueyffier F, Ayala A, Monneret G, Venet F: Programmed death-1 levels correlate with increased mortality, nosocomial infection and immune dysfunctions in septic shock patients. Crit Care 2011, 15:R99.

48. Hotchkiss RS, Opal S: Immunotherapy for sepsis - a new approach against an ancient foe. N Engl J Med 2010, 363:87-89.

\section{doi:10.1186/cc10333}

Cite this article as: Venet F, et al.: Clinical review: flow cytometry perspectives in the ICU - from diagnosis of infection to monitoring of injury-induced immune dysfunctions. Critical Care 2011, 15:231. 